\title{
Social Lifts Must Go Upstairs: Artificial Input and Mechanisms of Language Acquisition by Children *
}

\author{
Maria D. Voeikova
}

Institute of Linguistic Studies, Russian Academy of Sciences, Tuchkov per. 9, Saint Petersburg 199053 Russian Federation

\begin{abstract}
Children need a rich linguistic input for the sake of better mastering of their native language. However, for many socioeconomic reasons they lack it if their parents 1) belong to the low SES families and are not motivated enough to educate their children; 2) are migrants and do not fluently speak the language of the surrounding; 3) are well-doing and professionally motivated but do not have enough time to communicate with their children; or if the children 4) demonstrate language deficits and disorders. We propose to create an Artificial Input Machine (AIM) with language-specific content organized as samples of Child-Directed Speech (CDS) that benefit from using of the "bootstrapping mechanisms" of the given language. The proposal described here is based on Russian data.

Index Terms - language acquisition, input, socio-economic status (SES), language proficiency, artificial input devices.
\end{abstract}

\section{Introduction}

Recent investigations of L1 acquisition by children have shown the fundamental role of parental input for the better language proficiency of a child; see [1], among many others. The rich input not only helps children to master morphologically and phonologically rich languages [2] but also provides the psychological comfort and stability [3]. However, little children in many countries lack necessary linguistic input due to the fact that parents either have no time to speak with their kids (that normally happens in the families with a high socio-economic status (henceforth - SES)), or do not correctly understand the importance of such communication (characteristics of the lower SES families). The modern technical and linguistic opportunities allow creating a special device to fill in the gap between children's needs and the parental negligence. Our goal is to elaborate the linguistic basis for an artificial input machine (AIM) and to discuss the technical details of its production.

\section{Theoretical Framework: Usage-based Theories of Language Acquisition}

Theoretical linguistics of the last decades is characterized by the growing impact of usage-based theories of language description, e.g. [4], and, especially, of language acquisition [5] opposed to the earlier dominating generative approach [6]. Numerous investigations in different countries have shown that parents speaking to their children 1) effectively use different control and linguistic strategies [7]; 2) adapt their speech to the growing language competence of their children [8]; 3) organize their speech in such a way that some of its details serve as bootstraps for the language patterns to be acquired [9].
Usage-based theories stress the fact that al least some part of language forms and expressions is rote-learnt. Thus, the intensive listening to linguistic models and patterns strengthens children's ability to speak, whereas the extreme poverty of stimulus leads to language deficits [10]. Ref. [10] stresses the fact that children from low SES families in Israel get lexically poor and syntactically defective input that keeps them from the effective learning of their native language. Such children lag behind their peers starting from 1,5 year of life and the gap between them grows dramatically in the future couple of years. Thus, they have no opportunity to get better education at school and feel frustrated during their school years [11].

However, our first observations of children from families with different SES show that higher educated mothers are not simply more talkative with their children: they rather use a very sensitive fine-tuning strategy [12]. Another observation demonstrates that child developmental scales and inventories are predisposed to better evaluate children from higher SES families with extra developed narrative skills and lexicon. Thus, concerning L1 acquisition, the existing "social lifts" only take children from poor families downstairs. To avoid this undesirable tendency, specialists may start intervening into the process from the earliest periods of language development and later on re-estimate the validity of the existing methods of language control in preschoolers if necessary.

An Artificial Input Machine (AIM) providing language training to those children who lack the necessary input may fulfill the first task. In the following parts of this paper we shall sketch which kids may be objects for such training and give proposals for the linguistic content and technical requirements of the future device.

\section{Families That Need Help in Providing Linguistic Input for Their Children}

Saying that children from low SES families lack the appropriate language input does not mean that SES is the only factor that influences the process of L1 acquisition. In our longitudinal observation of one village child from the lowincome family in Russia we have found that the youngest child in a family (a granddaughter of the main caregivers) demonstrated an extremely high vocabulary score and early morphological patterns of development corresponding to her biological age (of 3;2) or even going ahead of the latter. This was in a striking contrast to her three and four years elder uncle and aunt that demonstrated both lexical and grammatical deficit. Since all children in the family had exactly the same

\footnotetext{
${ }^{*}$ This investigation was supported by Russian Scientific Foundation, grant N 14-18-03668 (to M.D. Voeikova)
} 
input we may explain this difference by inborn capacities of children, or by the higher level of empathy of caregivers to the granddaughter compared to their own children. Having given birth to 7 children, the grandmother of the girl under observation never got enough social support to live without working, as in the case described in [10]. The necessity to look for temporary jobs has changed her mind and social behavior. Last but not least, this mother (and grandmother) was the tenth child in her own family and has an experience of living in a big community and an inborn feeling of sharing attention and maintaining the dialogue with children. How did it happen that her own children were not as successful in learning the language as her granddaughter?

Being the youngest child in a big family the girl got attention not only from her sibling uncles and aunts and from her young mother but also from the grandmother and grandfather that demonstrated strong affection to her. In spite of this, her grandfather could not support her linguistic development with his poor and obscene lexicon and his extremely improper and nasty manners. He does not change style speaking to his wife, elder and younger children. Unlike this, the grandmother controls her speech addressing little children. Speaking to her daughter (a $1^{\text {st }}$ grade schoolgirl) she is friendly but insistent and shows a high positive control strategy, whereas with her granddaughter she chooses an extremely friendly high guidance strategy [7]. This case study shows that members of one and the same family demonstrate different linguistic and developmental strategies addressing to children. In this case, the successful behavior of only one caregiver was enough for the child to develop sufficient language proficiency.

The input deficit is registered if most members of the family neglect the child or are not capable of supporting her with a rich and child-directed input. The use of AIM in such families should be recommended by social services in order to provide equal rights to young citizens of the country irrespective of their starting conditions.

Another possible users of AIM are parents of bilingual children living in a foreign cultural and linguistic environment. These parents should be interested in using AIM to adapt their children to the surrounding.

The third group of users consists of parents with a strong professional motivation who lack time for communication with their children.

The last group comprises parents of children with developmental disorders who might profit from the bigger than usual input. Categories 2-4 should be interested in getting and trying the device themselves.

\section{Possible Modifications of AIM and Its Contents}

The simplest AIM is a screen with a balanced linguistic content including fairy tales, animated cartoons, stories presented by professional and non-professional readers. The content of the device should be changed after some intervals, e.g. once in half a year to correspond to the increasing linguistic proficiency of the child. The principal difference from a TV set or PC consists in its capacity to interact with children. For this purpose, the device should be supported by analytic tools reacting to the occurrence of children in the room, to their movements, to their vocalizations and changing positions. These tools are aimed to imitate attention-getting strategies of adult caregivers, e.g. the use of visual movements of the face to more effectively gain and maintain the attention of infants. Thus, the protagonist on the screen should try to attract the child's attention with a "cooing" intonation pattern typical for the child-directed speech (henceforth - CDS). Ideally, the device should fix the child's face position, her eye movements and body position, especially, when she falls down or cries. The device should react to the changing positions of a child, or her movements with appropriate comments providing her with socially approved behavioral patterns. Ideally, the device should also have an opportunity to follow the behavior of adult caregivers and prevent violence in the family.

Ideal parents use CDS for the creation of positive relationship to their kids. The high level of mutual acceptance is an important prerequisite for successful language learning [12]. The most important task of AIM is a stimulation of psychological contact with a child and a consecutive support of her linguistic progress. Therefore, the input should contain texts of different genres, like narratives and typical formulaic expressions; imitate dialogues and stimulate children's initiative in their maintenance. But the most important requirement is the linguistic variety of the input.

\section{Characteristics of Language-Specific Input (Case of Russian)}

CDS is a clear and simplified way of communicating to little kids not only used by adults but also by elder siblings. The vocabulary is limited, the speech temp is showered with a big number of pauses; the speech partners use to repeat sentences changing the order of their components and, thus, helping to introduce word and morphemic boundaries. Sentences are short and grammatically simplified. CDS uses different language-specific bootstrapping mechanisms [13], the extra linguistic cues helping children to apply the rules of their native language without really understanding them. Bootstrapping in this sense is based on partial parallelism between the units belonging to different language levels, e.g. prosodic and syntactic structures, or between lexical and semantic units and their syntactic surrounding. According to the patterns involved, prosodic, lexico-semantic, conceptual, morphosyntactic and pragmatic types of bootstrapping are distinguished. E.g. Russian-speaking adults use special "gender" shifts, reduplications, easy syntax and high pitch [14]. Ref. [14] also points to a particular register of communication with little kids that do not yet speak themselves. In this kind of communication, parents are not strictly oriented to the language proficiency of their kids; they just use the external patterns of CDS without simplifying their lexicon and grammar. Thus, we propose to also divide the content into two parts aimed for 1) not yet speaking children and for 2) those children who already produce verbal reactions. 
The first part of the content should make up the child's mind and teach her to communicate with the device including switching it on and off, keeping attention on the screen and reacting to verbal appeals. The second part of the content should be based on language-specific properties of the child's target language and make use of these properties as strongly as needed. We shall sketch the particular features of linguistic content basing on our findings for Russian.

Russian CDS was an object of several specialized investigations $[14,15]$ that may serve as a base for the content of AIM. We also make use of the existing observations of child Russian, especially its morphological and syntactic cues $[16,17]$.

E.g., about $70 \%$ of first words of Russian children contain reduplicated syllables, e.g. tjutju 'hide-and seek,' kaka 'bad and dirty things'. They occur as a model of syntactic phrase: pojdem-pojdem 'let's go-let's go', poka-poka 'bye-bye' and as a model of inflectional form: tjutju 'it disappears,' bobo 'it hurts,' gagak 'goose', tatas' 'karandash'. The latter forms first occur in children' speech but may be maintained by the adult family members. Reduplications and other extragrammatical operations [18] serve as a model for future morphological operations. Reduplications imitate grammatical forms of inflecting languages: they give children the idea that word forms have a binary structure. Back-formations present a model of paradigm with a constant stem and different inflectional endings. Actually, many kinship terms in Russian are back-formations and/or reduplications; compare mama and papa - reduplications and back-formations from matuška and batjuška, or baba from babuška. These words were accepted and reintroduced into the adult language from baby talk. Blends and rhyming words serve as a model of future inflectional classes. The advanced version of AIM should include such word-formation patterns, especially for the kids with language disorders.

Slavic and Baltic languages are characterized by a high frequency of diminutives in child and child-directed speech. Diminutives not only have important pragmatic functions but also facilitate the acquisition of morphology. However, it should be noticed that the frequency of diminutives varies greatly between native-speakers of every language. In Russia some mothers and also fathers (especially young and educated ones) assume that children should not receive the artificial, "bad taste" input. On the contrary, elder caregivers, especially grandmothers, are fond of using diminutives. However, in the only case when we could make calculations for the input from a Russian mother and a grandmother of the same child, the percentage of diminutives in their speech was comparably low in both cases, especially in the speech of the grandmother (grandmother: $34.9 \%$ of diminutive types vs. $27.8 \%$ of diminutive tokens; mother: $40.9 \%$ of diminutive types vs. $35.5 \%$ of diminutive tokens). In other cases, their percentage may reach $50 \%$ of all nouns in Russian CDS [9] whereas in Russian CS this percentage varies from $20 \%$ to $35 \%$ ). Diminutives in child-directed situations often occur in orders, requests, prohibitions, and questions: the use of diminutives mitigates the strictness of the speech act. To make use of this powerful device of language structuring in AIM, we should create texts with the different level of diminutive use. Children with a sufficient speed of morphological development may get a moderate percentage of diminutives in the input (35\% was the lowest empirical value for diminutives in Russian CDS). However, children with different disorders and deficits in L1 acquisition need more diminutives to start using nominal declension earlier.

At the advanced stage of morphological development children have a good command of using inflectional contrasts in verbs and nouns; make miniparadigms from the most frequent words and proceed to the elaborated syntax: their utterances contain 2-3 words or even more and have a clear syntactic structure. However, their language system is far from being adult-like: chidren still make many mistakes in nonproductive words and forms, produce erroneous pronoun forms and do not use adjectives correctly. The late acquisition of adjectives presents here a big and interesting problem.

At the earliest stages of their language development children do not fully distinguish adjectives from nouns. This may be illustrated by several facts. Children mix adjectives belonging to the same semantic class. As we proposed earlier in [14], basing our assumptions on the case study of a boy Philipp, this fact may be explained by the mother's strategy of grouping adjectives into "multiple choice" questions of the type "What colour is the car: green, yellow or red?" Due to this strategy children get accustomed to use adjectives in semantic clusters but are far from being aware of their individual meaning.

Children treat adjectives as a special kind of noun that is abstract, occurs in contrasting pairs and denotes the same object as a common noun. According to the data from parental responses to questionnaires used by the Institute of Early Intervention in Saint Petersburg, the average age of production for several colour adjectives corresponds to the age of their first comprehension whereas in the case of object naming comprehension usually precedes production. First adjectives in child speech are used without nouns (all our four informants for this study used more than $85 \%$ of all adjectives without their head nouns in the three first months of the observation). A clear difference exists between the early talking children and their late talking peers. The early users of adjectives keep to the isolated adjective use for longer: eight months after the first occurrences of adjectives in a boy's speech $80 \%$ of them still lack their head nouns. Another informant, a girl of the same age, managed to do a bit better having achieved $46 \%$ of isolated adjectives after 5 months of their onset.

All our subjects demonstrate a period of the sporadic use of the adjectives. Adjectival forms were extremely rare and mostly isolated. This period is followed by a so-called "adjective spurt" when they suddenly start using dozens of adjectives per hour of recording. Isolated use of adjectives is not ungrammatical in adult spoken Russian (especially, in a dialogue); therefore we do not expect that children will completely stop producing these forms. However, the decline in their usage (by up to 50\%) points to the syntactic dissociation of adjectives from nouns. At the same time 
children use more correct inflectional suffixes, marking case, number and gender differences not only on nouns but also on the adjectives. At this stage they rather use similar, partly similar and reduplicative inflectional endings. However, this is not only due to the phonological bootstrapping provided by these forms but also due to the fact that the latter are more basic in the declension system (being both frequent and productive).

A clear preference for phonological similarity of the adjectival and nominal inflectional endings may be illustrated by children's errors. Some of our subjects clearly tend to assimilate the inflectional endings of adjectives and nouns. Sometimes they even change the noun for the sake of making it similar to the adjective. Assimilating errors in our informants make from $42 \%$ to $73 \%$ of all erroneous adjectival forms. However, this tendency was only registered at 2;3, a month after the adjective spurt. Until this point children also make dissimilating errors. Thus, they tend to profit from the phonological resemblance of the adjectival and nominal suffixes to a different degree and at different stages in their development.

We are going to use bootstrapping mechanisms of Russian language for AIM content trying to increase the percentage of language means facilitating language acquisition of particular lexical and grammatical items. Now, we are collecting the input samples for the first version of AIM and look for the opportunity to measure its effectiveness on children speech ability. The second stage consists in the further elaboration of children-oriented contents and in the development of technical means of interaction with little children.

\section{Discussion and Conclusions}

Our proposal is based on the existing investigations of Russian CDS and child speech; however, we are not sure whether our knowledge of the input properties of Russian (and every other language taken for this goal) is enough for modeling the rich linguistic input. Extra analysis is needed to calculate the necessary parameters of the contents concerning its genres, the imitation of spontaneous interaction, the percentage of bootstrapping means that are necessary in every concrete case. Here, we should take into consideration the dialogical competence of the speakers, since artificial communication does not fully correspond to the natural one. Neither did we say a word about children's and adult Theory of Mind, or expectations of speech partners concerning the partner's awareness of things. However, these topics may also get attention in the future development of the device.

We sketched the main principles of such model claiming that the content of a future AIM should be based on the recent stage of children's development and should be child-oriented in future. The ideal device must be able to fine-tuning to every individual child. We are going to make use of the internal properties of the given language and to find out which bootstrapping mechanisms play the most important role in its acquisition. We could notice that economical development and scientific progress of the last twenty years had yet no decisive positive impact on children upbringing. Socioeconomic inequity has negative consequences not only for every individual but also for the their native countries. Our technical and scientific knowledge allows an attempt to change the situation now.

\section{References}

[1] M. L. Rowe, "Child-directed speech: relation to socioeconomic status, knowledge of child development and child vocabulary skill," Journal of Child Language, vol. 35, pp. 185-205, 2008.

[2] A. Xanthos et al., "On the role of morphological richness in the early development of noun and verb inflection," First Language, vol. 31, no. 4, pp. 461-479, 2011.

[3] P. Kaplan, J. Dungan, and M. Zinser, "Infants of chronically depressed mothers learn in response to male, but not female, infant-directed speech," Developmental Psychology, vol. 40, no. 2, pp. 140-148, 2004.

[4] M. Barlow, and S. Kemmer (Eds.) Usage-based models of language. Stanford, CSLI, 2000.

[5] M. Tomasello, M. Constructing a Language: A Usage-Based Theory of Language Acquisition. Cambridge, MA/London: Harvard University Press, 2003.

[6] Valian V. Input and Innateness: Controversies in Language Acquisition. Cambridge, MA: MIT Press, 2012.

[7] N. Taylor, W. Donovan, S. Mills, and L. Leavitt, "Maternal control strategies, maternal language usage and children's language usage at two years," Journal of Child Language, vol. 36, pp. 381-404, 2009.

[8] P. Kuhl et al. "Cross-Language Analysis of Phonetic Units in Language in Language Addressed to Infants," Science, vol. 277, no. 5326, pp. 684$686,1997$.

[9] I. Savickienė, and W. U. Dressler (eds.) The Acquisition of Diminutives: A cross-linguistic perspective. Language Acquisition and Language Disorders, 43. Amsterdam/Philadelphia: John Benjamins Publishing Company, 2007.

[10] R. Schiff, and E. Lotem, "Effects of phonological and morphological awareness on children's word reading development from two socioeconomic backgrounds," First Language: 139-163, 2012.

[11] OECD (2010). PISA 2009 Results: Overcoming Social Background Equity in Learning Opportunities and Outcomes (Volume II), http://dx.doi.org/10.1787/9789264091504-en, 21.05.2013

[12] R. Zh. Muhamedrahimov, Mother and Child: Psychological Interaction (in Russian). Saint Petersburg: Saint Petersburg State University Publ.,1999.

[13] Ju. Weissenborn, and B. Höhle (eds.) Approaches to Bootstrapping: Phonological, lexical and neurophysiological aspects of early language acquisition Amsterdam/Philadelphia: John Benjamins Publishing Company, 2001.

[14] M.D. Voeikova, Early stages of children's acquisition of Russian nominal morphology [in Russian: Rannie stadii usvoenija det'mi imennoj morfologii russkogo jazyka]. Moscow: Znak, 2011.

[15] T.O. Gavrilova, The Register of Communication with Children: Structural and Sociolinguistic Aspects (based on Russian data) [in Russian: Registr obščenija s det'mi: strukturnye i sociolingvističeskie aspekty). Unpublished doctoral dissertation. Saint Petersburg, European University of Saint Petersburg, 2002.

[16] S. N. Ceitlin, Essays in Word-and Form-Building in Child Language [in Russian: Očerki po slovoobrazovaniju i formoobrazovaniju v detskoj reči]. Moscow: Znak, 2009.

[17] M.B. Eliseeva, Phonological and Lexical Development of a Little Child [in Russian: Fonologičeskoe i leksičeskoe razvitie rebenka rannego vozrasta]. Saint Petersburg: Herzen RGPU, 2008.

[18] W.U. Dressler (ed.) Studies in Pre- and Protomorphology. Wien: Verlag der Akademie der Wissenschaften, 1997. 